\title{
Effect of a Matrix Modifier on the Temperature Change during Atomization Process in Graphite Furnace Atomic Absorption Spectroscopy
}

\author{
Yasushi Terui*, Kazuo YaSudA** and Kichinosuke Hirokawa* \\ *Institute for Materials Research, Tohoku University, Katahira, Sendai 980, Japan \\ **Naka Works, Hitachi Ltd., Katsuta, Ibaraki 312, Japan
}

\begin{abstract}
The gas temperature of a graphite furnace was measured by a two line atomic absorption method using $\mathrm{Pb}$ lines. The correction factor of this method was calculated by assuming the gas temperature of the air-acetylene flame to be $2600 \mathrm{~K}$. The effective vapor temperature in the presence of a matrix modifier was higher than that in the absence of the modifier. One of the reasons is that the Pd matrix modifier delays the appearance time of the absorption signal to a higher temperature. The other is that the atoms or molecules of the modifier transfer energy to the analyte atoms, thus exciting them. This means that the gas phase is not in thermal equilibrium, and that the electron temperature had soared. It is thought that the temperature is somewhere different between the gas and electron temperatures.
\end{abstract}

Keywords Effective vapor temperature, graphite furnace, two line atomic absorption method, matrix modifier, electron temperature

Ashing-temperature raising, lessening matrix interference and improving the sensitivity by adding a matrix modifier have been well-known techniques. ${ }^{1-6}$ It has been recognized that $\mathrm{As}, \mathrm{Pb}, \mathrm{Mn}, \mathrm{Cr}$, and others, form alloys with $\mathrm{Pd}$ or $\mathrm{Ni}$ when added to the samples as a matrix modifier. These alloys do not evaporate until reaching a higher ashing temperature; further, they undergo flash atomization at higher atomization temperatures, and can improve the sensitivity. Still, there have not been many studies regarding changes in the gas and electron temperatures in a furnace during atomization and residence processes.

There have been several studies concerning the effective vapor temperature: Chakrabarti et al. reported a effective vapor temperature of about $200^{\circ} \mathrm{C}$ lower than the wall temperature of the furnace; Frech et al. studied the relation between the furnace geometry and the effective vapor temperature; and de Galan commented, "Does thermal equilibrium exist in a furnace?"

The main purpose of this study was to investigate any change in the gas and electron temperatures during atomization in a furnace.

\section{Experimental}

A Hitachi Model Z-9000 multi-channel atomic absorption spectrometer was used for measuring the effective vapor temperature using the two-line atomic absorption method; the atomic absorption of other two analyte elements could be measured simultaneously.
The optical system of the graphite furnace was as follows: four light beams were crossed at the central part of the furnace; they almost coincided with each other at a dented place into which a sample was loaded. ${ }^{14-16}$ Therefore, any error resulting from optics mismatching was thought to be small in all effective vapor temperature measurements using the two-line method.

A Hitachi Model Z-8100 atomic absorption spectrophotometer with an air-acetylene flame was used to obtain a correction factor for the gas temperature measurements. Both of the instruments (Z-9000 and Z8100) are polarized Zeeman effect-atomic absorption spectrophotometers.

We used two kinds of temperature-control systems for the furnace. One was a pyrometric control method in which the wall temperature was monitored and its heating current controlled by feeding back the value of the monitored temperature. The other one kept the heating current constant. The temperature-raising speed of the furnace in the former method was faster than that in the latter. A pyrolytic carbon tube was used as the graphite furnace.

The effective vapor temperature was measured by the two-line atomic absorption method using the $\mathrm{Pb}$ $280.2 \mathrm{~nm}$ and $368.3 \mathrm{~nm}$ lines. Since the lower states of these lines were not a ground state, the sensitivity of atomic absorption was poor. We therefore used a sample with a concentration of $100 \mu \mathrm{g} / \mathrm{ml}$ and a volume of $10 \mu \mathrm{l}$. Both sampling and injection of the solution into the furnace was carried out with an auto-sampler; the reproducibility was about $1 \%$ when we used a sample 
concentration of $10-100 \mathrm{ng} / \mathrm{ml}$ and a volume of $10 \mu \mathrm{l}$ under normal conditions.

\section{Results and Discussion}

The variation of the wall and effective vapor temperatures as a function of the atomization time are shown in Figs. $1 \mathrm{a}, 1 \mathrm{~b}, 2 \mathrm{a}$ and $2 \mathrm{~b}$. The experimental conditions for the graphite furnace are shown in Table 1. The data given in Fig. 1 were obtained by the pyrometric control method; data obtained by the constant current heating method are shown in Fig. 2. The speed of temperature raising in the former was faster than that in the latter.

$\mathrm{Pd}, \mathrm{Ni}, \mathrm{Pt}$ and $\mathrm{Mg}$ were chosen as the matrix modifier, since these elements have been widely used. As a reference, $\mathrm{K}$ was used as an element which shows a high vapor pressure and a low ionization potential. Ti was chosen as a typical element which can be used to make carbide. As an element having a vapor pressure be-
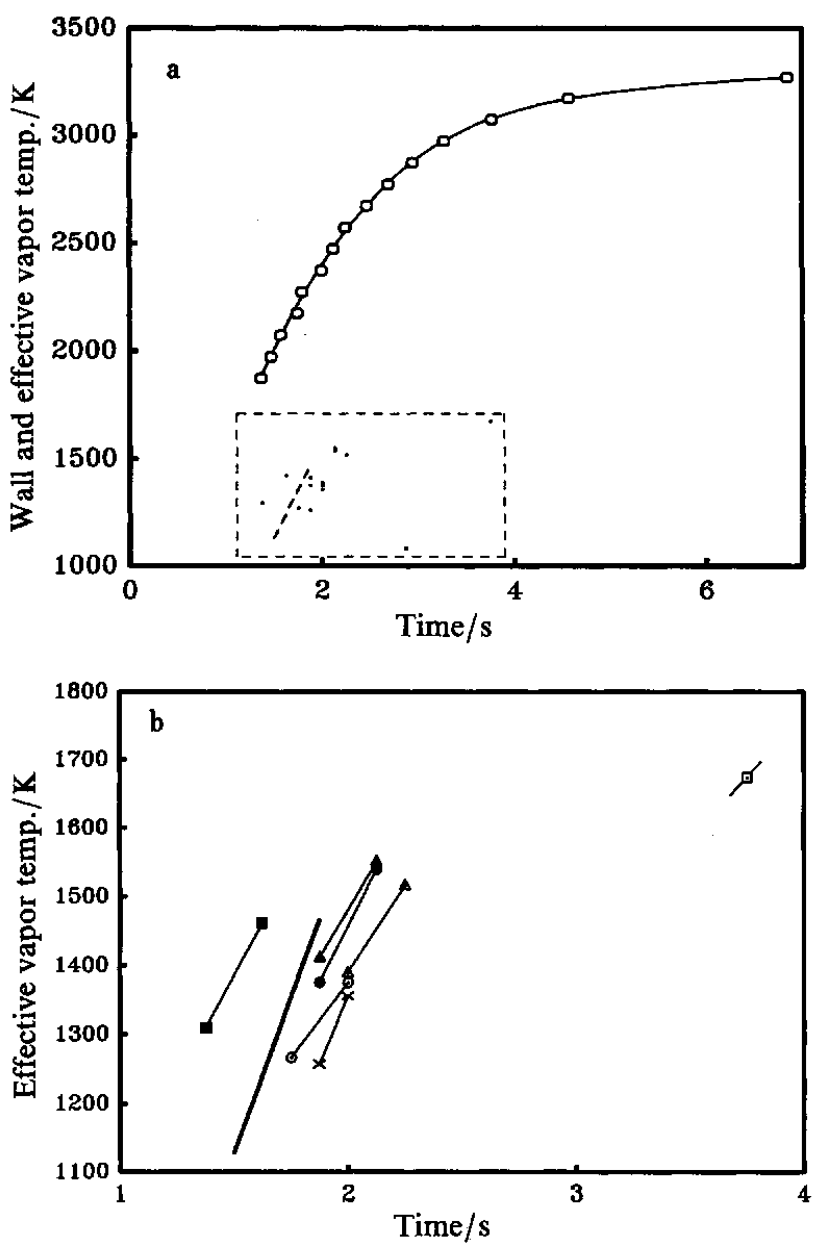

Fig. 1 (a) Variations of the wall temperature ( $\square$ ) and effective vapor temperature (in the box of dashed line) as a function of atomization time in a pyrometric-control method. (b) Magnified the box (dashed line) in (a). Matrix modifier: $\mathrm{O}, \mathrm{K} ; \mathrm{O}, \mathrm{Y} ; \square, \mathrm{Pd} ; \mathbf{G}, \mathrm{Mg} ; \Delta, \mathrm{Pt} ; \mathbf{\Delta}, \mathrm{Ni} \times \times, \mathrm{Ti}$. The solid line is temperature raising process in absence of matrix modifier. tween that of $\mathrm{Pd}$ and $\mathrm{Pt}$, and different chemical characteristics, $Y$ was chosen. The concentration of these matrix modifiers was $100 \mu \mathrm{g} / \mathrm{ml}$, at a volume of $10 \mu \mathrm{l}$.

The absorptions occurring from higher excited states and the ground states of $\mathrm{Ni}$ and $\mathrm{Bi}$ were measured, and are shown in Figs. 3 and 4. Each absorption recording
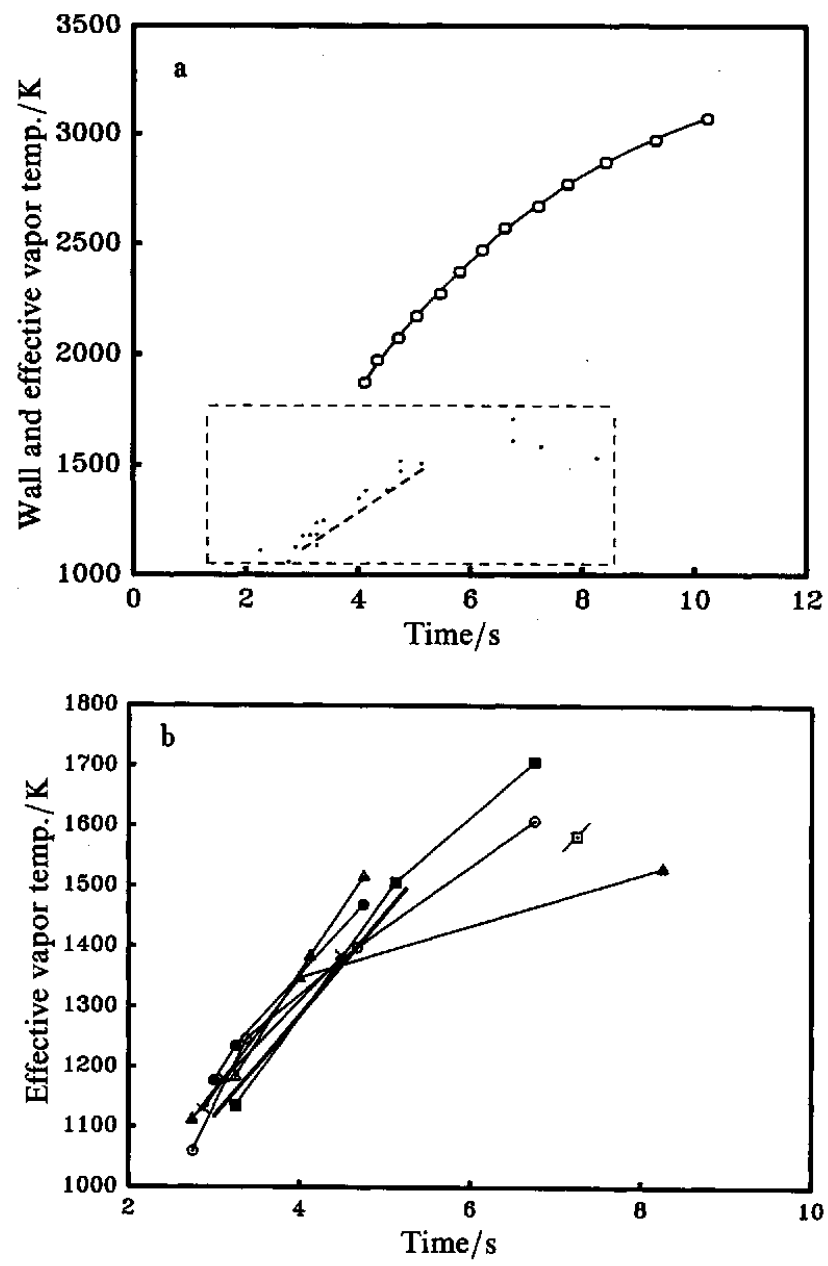

Fig. 2 (a) Variations of the wall temperature $(\square)$ and effective vapor temperature (in the box of dashed line) as a function of atomization time in a constant-current heating method. (b) Magnified the box (dashed line) in (a). Matrix modifier: O, K; , Y; $\square, \mathrm{Pd} ; \mathbf{\square}, \mathrm{Mg} ; \Delta, \mathrm{Pt} ; \boldsymbol{\Delta}, \mathrm{Ni} ; \times$, Ti. The solid line is temperature raising process in absence of matrix modifier.

Table 1 Experimental conditions for graphite furnace in Figs. 1a-4

\begin{tabular}{lcc}
\hline & Temperature $/{ }^{\circ} \mathrm{C}$ & Time $/ \mathrm{s}$ \\
\hline Drying & $80 \rightarrow 120$ & 30 \\
& (start) (end) & \\
Ashing & 300 & 30 \\
Atomizing & 3000 & 10 \\
Cleaning & 3000 & 5 \\
\hline
\end{tabular}

Temperature is controlled by pyrometric method for Figs. 1a, $1 \mathrm{~b}, 3,4$ and by constant current heating method for Figs. 2a and $2 b$. 
was obtained under conditions both with and without a modifier.

The $\mathrm{Pb} 368.3$ and $280.2 \mathrm{~nm}$ lines used for temperature measurements originated from the $6 \mathrm{p}^{3} \mathrm{P}_{1} \rightarrow 7 \mathrm{~s}^{3} \mathrm{P}_{0}$ and $6 p^{3} P_{2} \rightarrow 6 d^{3} F_{3}$ transitions. The energy level of $6 p^{3} P_{1}$ and $6 \mathrm{p}^{3} \mathrm{P}_{2}$ are located at $7819.4 \mathrm{~cm}^{-1}$ and $10650.5 \mathrm{~cm}^{-1}$ above the ground state, respectively. The measured value using the two-line atomic absorption method is a product of the density of atoms at the states of $6 p^{3} P_{1}$ or $6 p^{3} P_{2}$, and transition probability of the atoms from these states to $7 \mathrm{~s}^{3} \mathrm{P}_{0}$ or $6 \mathrm{~d}^{3} \mathrm{~F}_{3}$. The important fact is that the transition probability in this method is not the integrated one, but the one is a weighted mean of the profile of the absorption line and the overlapped profile of the emission line from the light source. In other words, the product of the line intensity and the transition probability is the so-called transition probability in this situation. It is therefore impossible to obtain the transition probability if the absorption and emission line profiles are not determined.

Furthermore, since the absorption line is split by the Zeeman effect, it is more difficult to obtain the absorption line profile. The transition probability in this case, is therefore obtained by measuring the two kinds of absorption by the two-line method using an air-acetylene flame with an assumed temperature of $2600 \mathrm{~K}$; then, the ratio of the gf values corresponding to each absorption line can be calculated.

The temperature deduced by the two-line $\operatorname{method}^{17}$ is:

$$
\ln \left(\frac{g_{\mathrm{q}^{*}} \cdot A_{\mathrm{qp}} \cdot \nu_{0}}{B\left(\mathrm{em}_{1}\right)}\right)-\ln \left(\frac{g_{\mathrm{q}^{*}} \cdot A_{\mathrm{q}^{\prime} \mathrm{p}^{*}} \nu_{0}}{B^{\prime}\left(\mathrm{em}_{2}\right)}\right)=\frac{E_{\mathrm{q}}-E_{\mathrm{q}^{\prime}}}{k \cdot T_{\mathrm{eff}}}
$$

where $g_{\mathrm{q}}$ and $g_{\mathrm{q}^{\prime}}$ are degeneracies of the energy levels $\mathrm{q}$ and $\mathrm{q}^{\prime}$. $A_{\mathrm{qp}}, A_{\mathrm{q}^{\prime} \mathrm{p}^{\prime}}$ are the spontaneous emission transition probability coefficients from $\mathrm{q}$ or $\mathrm{q}^{\prime}$ to the $\mathrm{p}$ or $\mathrm{p}^{\prime}$ energy levels. $B$ and $B^{\prime}$ are the induced values; $E_{\mathrm{q}}$ and $E_{\mathrm{q}}$ represent the energy difference from the ground state; $k$ is Boltzmann's constant; $\nu_{0}$ is a central wavenumber of the atomic emission line; and $T_{\text {eff }}$ is the effective vapor temperature. As already mentioned above, the transition probability coefficient used in the two-line atomic absorption method can not be expressed in the form $A_{\mathrm{qp}}$ or $A_{\mathrm{q}^{\prime} \mathrm{p}^{\prime}}$, but should be written as $A_{\mathrm{qp}} P(\nu$. abs.) $P(\nu \cdot$ em. $)$ Here, both $P$ are profile functions of the absorption line and the emission line of the light source. Eq. (1), however, can be expressed simply by Eq. (2), in a manner after Siemer et al.:7,11,18

$$
T_{\text {eff }}=\frac{\Delta E}{\ln \left(\frac{\text { Abs. } \mathrm{P}_{1}}{\text { Abs. } \mathrm{P}_{2}} \times f(\text { tran.prob. })\right)} .
$$

Here, Abs. $P_{1}$ is the absorbance by the $6 p^{3} P_{1} \rightarrow 7 s^{3} P_{0}$ $(368.3 \mathrm{~nm})$ transition. Abs. $P_{2}$ is the absorbance by the $6 \mathrm{p}^{3} \mathrm{P}_{2} \rightarrow 6 \mathrm{~d}^{3} \mathrm{P}_{3}(280.2 \mathrm{~nm})$ transition; $f$ (tran.prob.) is the ratio of the transition probabilities of both $g_{\mathrm{q}} A_{\mathrm{qp}} P(\nu$. abs.) $P\left(\nu^{*} \mathrm{em}\right.$. $)$ mentioned above; $\Delta E$ is the energy difference between the two energy levels.

Since the temperatures of an air-acetylene flame are reported to be scattered from 2398 to $2598 \mathrm{~K}^{19}$, especially for the lower temperatures obtained by a mixed gas of methane-acetylene, we therefore assumed a temperature of $2600 \mathrm{~K}$. Abs. $P_{1}$ and Abs. $P_{2}$ were measured with an air-acetylene flame. $\Delta E$ is $2831 \mathrm{~cm}^{-1}\left(10650.5 \mathrm{~cm}^{-1}-\right.$ $\left.7819.4 \mathrm{~cm}^{-1}\right)$. We then obtained 1.44 for the value of $f$ (tran.prob.). The resulting equation is

$$
T_{\mathrm{eff}}=\frac{2831}{\ln \left(1.44 \times \frac{\text { Abs.P }}{\text { Abs.P }_{2}}\right)}
$$

These effective vapor temperatures are shown in Figs. 1a, $1 b, 2 a$ and $2 b$. It was found from Fig. 1 that the effective vapor temperature reached its final value in the presence of a modifier of $\mathrm{Pd}, \mathrm{Ni}, \mathrm{Pt}$ or $\mathrm{Y}$ higher than that in the absence of a modifier. The appearance time of $\mathrm{Pb}$ atoms in the presence of $\mathrm{Pd}, \mathrm{Ni}$ or $\mathrm{Pt}$ modifier was delayed and shifted to a higher temperature. Especially, the Pd modifier greatly delayed the appearance time of $\mathrm{Pb}$. $\mathrm{K}$ and Ti showed a different trend from that of $\mathrm{Pd}$, $\mathrm{Ni}$ and $\mathrm{Pt}$. Under the slow atomization process shown in Fig. 2, we could recognize the same trend as that in Fig. 1, in which the effective vapor temperature in the presence of the modifier was higher than in the absence of $\begin{array}{ll}\text { with-modifier } & \text { without-modifier } \\ \text { Eff. temp. }=2383 \mathrm{~K} & \text { Eff. temp. }=1348 \mathrm{~K}\end{array}$

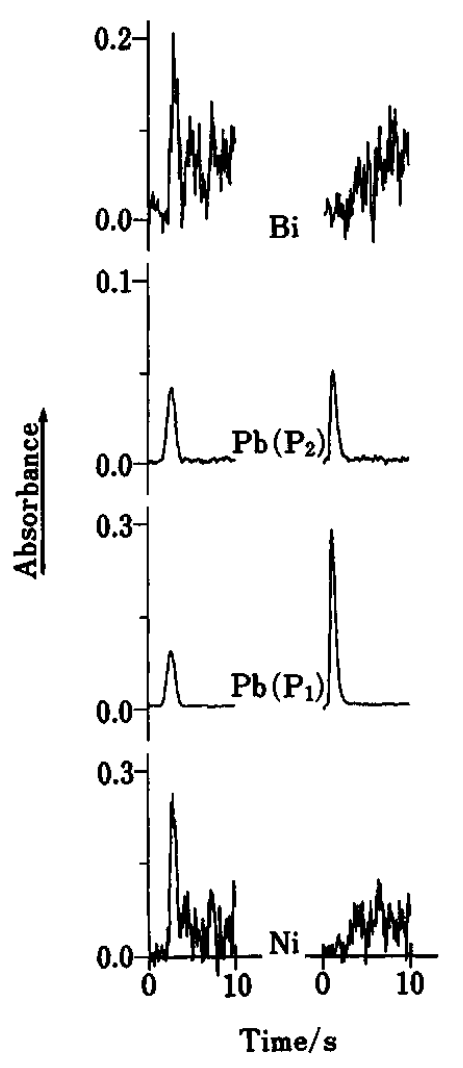

Fig. 3 Absorption from the excited state of $\mathrm{Bi}$ and $\mathrm{Ni}$. Wavelength: $\mathrm{Bi}, 472.2 \mathrm{~nm} ; \mathrm{Ni}, 676.8 \mathrm{~nm}$. Concentration: $\mathrm{Bi}, 1 \mu \mathrm{g} / \mathrm{ml} ; \mathrm{Ni}, 10 \mu \mathrm{g} / \mathrm{ml}$. 
a modifier.

If the temperature is made higher by adding a matrix modifier, absorption in a higher excited state would be expected to occur. From the absorption signal of the excited state of $\mathrm{Bi}$ or $\mathrm{Ni}$ in Fig. 3, the effective vapor temperature was calculated by using the peak height values of $\mathrm{Pb}$ absorption. It was found that absorption by a transition of $\mathrm{Bi}$ from $6 \mathrm{p}^{2} \mathrm{D}_{3 / 2}$ to $7 \mathrm{~s}^{4} \mathrm{P}_{1 / 2}(472.2 \mathrm{~nm})$ appeared upon the addition of a Pd matrix modifier; no absorption was observed in the absence of a modifier. The lower level of this absorption is located at 11418 $\mathrm{cm}^{-1}$ above the ground state. The same trend was observed in the case of $\mathrm{Ni}$. The transition of $\mathrm{Ni}$ from $3 \mathrm{~d}^{1} \mathrm{~S}_{0}$ to $4 \mathrm{p}^{3} \mathrm{P}_{1}(676.8 \mathrm{~nm})$ appeared in the presence of a matrix modifier, even if the lower level of this absorption was located at $14729 \mathrm{~cm}^{-1}$, much above the ground state.

It is necessary to study the absorption from the ground state as well as that from excited states in order to investigate the above-mentioned situation. Figure 4 shows the absorption signals from the ground state in both the presence and absence of a Pd modifier. The absorbance of 1.6 for $\mathrm{Bi}(223.1 \mathrm{~nm})$ in the absence of a modifier decreased to one tenth when a modifier was added. In the case of $\mathrm{Ni}(356.6 \mathrm{~nm})$, the absorption intensity also decreased to one half. This absorption of

$\begin{array}{ll}\text { with-modifier } & \text { without-modifier }\end{array}$

Eff. temp. $=2309 \mathrm{~K}$ Eff. temp. $=1368 \mathrm{~K}$

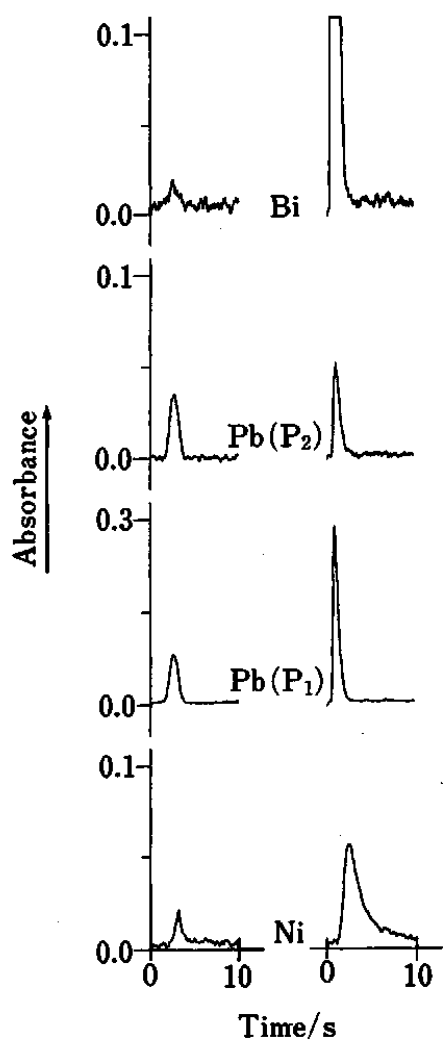

Fig. 4 Absorption from the ground state of $\mathrm{Bi}$ and $\mathrm{Ni}$. Wavelength: $\mathrm{Bi}, 223.1 \mathrm{~nm}$; Ni, $356.6 \mathrm{~nm}$. Concentration: $\mathrm{Bi}, 0.1 \mu \mathrm{g} / \mathrm{ml} ; \mathrm{Ni}, 1 \mu \mathrm{g} / \mathrm{ml}$.
Ni occurred from a level located at $3410 \mathrm{~cm}^{-1}$ above the ground state, which is very near to the ground state. The difference of the temperature between those with and without a modifier was about $1000 \mathrm{~K}$. It was found that the appearance of a $\mathrm{Pb}\left(\mathrm{P}_{1}, \mathbf{P}_{2}\right)$ peak with a modifier was both delayed and shifted to a higher temperature in these figures. This evidence can be used to explain how absorption in the higher excited state takes place; still, it is difficult to explain why the atomic density of the ground state decreases.

It could be recognized that the analyte atom received energy in some ways from the atoms or molecules formed from the matrix modifier, and stayed in the excited state during the atomization process. These phenomena caused an increase in the atomic density in the excited state and increased the absorption intensity. In contrast, absorption was thought to decrease the atomic density of the ground state. It is difficult to consider that the increase of the absorption intensity from the excited state or decrease of the absorption from the ground state was caused only by a temperature increase or temperature shift upon adding a matrix modifier, since the decrease in the density of the ground state was too large, according to an estimation made using the Boltzmann equation. It is, therefore, necessary to assume that the atomic density of the excited state was increased due to collisions with coexisting atoms and molecules. In other words, the electron temperature increased. We therefore believe that the temperature of gas phase in a graphite furnace exists between the gas and electron temperature.

The authors thank Messrs. K. Harada and A. Yonetani at Hitachi Ltd. for their consideration extended to us.

\section{References}

1. Y. Ide, M. Yanagisawa, K. Kitagawa and T. Takeuchi, $J$. Spectrosc. Soc. Jpn., 24, 143 (1975).

2. R. D. Ediger, At. Absorption Newsl., 14, 127 (1975).

3. X. Shan and Z. Ni, Anal. Chem. Sinica, 37, 261 (1979).

4. G. Schlemmer and B. Welz, Spectrochim. Acta, 41B, 1157 (1986).

5. L. M. Voth-Beach and D. E. Schrader, Spectroscopy, 1, (10), 49 (1986).

6. S. Sakurada, H. Takahashi and M. Taga, Bunseki Kagaku, 38, 407 (1989).

7. C. L. Chakrabarti, S. B. Chang, T. J. Haston, J. T. Rogers, R. Dick and P. C. Bertels, Anal. Chim. Acta, 176, 17 (1985).

8. W. M. G. T. van den Brack, L. de Galan, J. P. Matousek and E. J. Czolik, Anal. Chim. Acta, 100, 121 (1978).

9. R. E. Sturgeon and C. L. Chakrabarti, Spectrochim. Acta, 32B, 231 (1976).

10. M. P. Bratzel, Jr. and C. L. Kirkbright, Anal. Chim. Acta, 84, 79 (1976).

11. D. Siemer and W. Frech, Spectrochim. Acta, 39B, 261 (1984).

12. W. M. G. T. van den Brack and L. de Galan, Anal. Chem., 49, 2176 (1977). 
13. B. Welz, M. Sperling, G. Schlemmer, N. Wenzel and G. Marowsky, Spectrochim. Acta, 43B, 1187 (1988).

14. K. Ohishi, T. Okumoto, A. Yonetani, M. Hashimoto and K. Yasuda, Proceedings of IUPAC 3rd International Congress, Sendai, 1988, p. 123.

15. K. Yasuda, T. Okumoto, A. Yonetani, H. Yamada and K. Ohishi, 5. Colloq. Atom. Spurenanalytik, 1988, 133.

16. K. Ohishi, J. Spectrosc. Soc. Jpn., 39, 88 (1990).
17. I. Reif, V. A. Fassel and R. Kniseley, Spectrochim. Acta, 28B, 105 (1973).

18. D. D. Siemer, Appl. Spectrosc., 37, 73 (1983).

19. R. Mavrodineanu and H. Boiteux, "Flame Spectroscopy", pp. $26-44$, Wiley, New York, 1965.

(Received September 24, 1990)

(Accepted March 15, 1991) 